Asian-Australasian Journal of

Food Safety and Security

ISSN 2523-1073 (Print) 2523-2983(Online)

www.ebupress.com/journal/aajfss

\title{
Article \\ Analysis of pesticide residue in vegetables collected from nine different regions of Bangladesh using Gas Chromatography
}

\author{
Md. Sultan Ahmed*, Afroza Begum, Mohammad Dalower Hossain Prodhan and Debasish Sarker \\ Division of Entomology, Bangladesh Agricultural Research Institute, Joydebpur, Gazipur-1701, Bangladesh \\ *Corresponding author: Md. Sultan Ahmed, Division of Entomology, Bangladesh Agricultural Research \\ Institute, Joydebpur, Gazipur-1701, Bangladesh. E-mail: sultan_palbari@yahoo.com
}

Received: 10 April 2019/Accepted: 15 May 2019/ Published: 30 May 2019

\begin{abstract}
The study was conducted to analyze the amount of residue of six commonly used pesticides (e.g. chlorpyriphos, quinalphos, diazinon, acephate, dimethoate and fenitrothion) in vegetables viz., hyacinth bean and eggplant samples collected from local market of nine different locations viz. Cumilla, Bogura, Rangpur, Rajshahi, Khagrachari, Cox's bazaar, Barishal, Jamalpur and Dhaka for the comparison between the detected residue level with maximum residue limit (MRL) set by European Union. Among 36 analyzed samples of hyacinth bean six samples $(16.67 \%)$ were contaminated with chlorpyriphos $(0.082 \mathrm{mg} / \mathrm{kg})$ and dimethoate residue $(0.192 \mathrm{mg} / \mathrm{kg}-0.961 \mathrm{mg} / \mathrm{kg})$, all of them were above maximum residue limit. Out of 36 analyzed samples of eggplant 3 samples $(8.33 \%)$ were contaminated with quinalphos $(0.081 \mathrm{mg} / \mathrm{kg})$ and dimethoate residue $(0.032 \mathrm{mg} / \mathrm{kg}-0.217 \mathrm{mg} / \mathrm{kg})$ which were above MRL. Most of the samples contained with dimethoate residue in both the vegetables. The presence of pesticide residue exceeding MRL in vegetables is harmful to human and other living organisms. Analyzed samples of Cumilla, Bogura, Rangpur and Rajshahi showed pesticide residue (i.e. dimethoate, chlorpyriphos and quinalphos) over MRL but the samples of other five locations like Cox's bazar, Khagrachari, Barishal, Jamalpur and Dhaka did not show any detectable residue which might safe for consumption.
\end{abstract}

Keywords: pesticide; residue; MRL; hyacinth bean; eggplant

\section{Introduction}

Bangladesh has an agricultural economy. Although food production has more than doubled since 1971, food security is still remains a major issue for it's huge population. To grow more agricultural production the use of agrochemicals is increasing rate at present. More intensive vegetable production is the common reliance of most vegetable producers on heavy application of pesticide (Hossain et al., 2000). Among the vegetables i.e. hyacinth bean and eggplant grown in Bangladesh, are nutritious, valuable and very popular to consumers. It has been reported that in eggplant and hyacinth bean the attack of insect pests are severe and farmers sprayed pesticides quite frequently even every day (Anon. 2001). The improvement of the food production technology and the demands of the new markets for better products both in quality and quantity have been made among others with intensive uses of pesticides for productivity warranty (Trevisan et al., 2004). Pesticide being toxic can become a potential hazard to the manufacturers, the user, the public at large and the environment. Pesticide can produce negative impacts, both social and private (Antle and Pingali, 1994). Extensive deliberate use of pesticides has resulted in contamination of our vital supplies, air, water and food. The risk to humans may be short term as well as long term depending on the persistence of the pesticide and the exposure period. Pesticide residue in food has become a consumer's safety issue and the consumers have the right to know how much pesticide get incorporated in the food they eat.The detection, identification and quantification of pesticide in the food becoming the public interest. But very little references are available on the presence of pesticides in vegetables in Bangladesh (Khatoon et al., 2004; Ahmed et al., 2013). Consedering these, the present study was undertaken 
to analyze and quantify the amount of residue of pesticide in hyacinth bean and eggplant collected from local market of nine different regions of Bangladesh.

\section{Materials and Methods}

The standard for chlorpyriphos, quinalphos, diazinon, acephate, dimethoate and fenitrothion were obtained from Sigma-Aldrich Laborchemikalien, Seelze, Germany via Bangladesh Scientific Pvt. ltd. Dhaka, Bangladesh. Standards of all the pesticides contained $>99.6 \%$ purity. Available vegetable samples viz., eggplant and hyachinth bean were collected from local market of different regions namely Cumilla, Bogura, Rangpur, Rajshahi, Khagrachari, Cox's bazaar, Barishal, Jamalpur and Dhaka.

\subsection{Extraction, separation and clean up}

The QuEChERS (Quick, Easy, Cheap, Effective, Rugged and Safe) method was used to extract pesticides from vegetables. The method was slightly modified. Collected vegetable samples were chopped on a chopping board with a sharp knife. $10 \mathrm{~g}$ of chopped sample was transferred into a $50 \mathrm{~mL}$ polypropylene centrifuge tube. Then $10 \mathrm{~mL}$ of acetonitrile $(\mathrm{MeCN})$ was added into centrifuge tube. The centrifuge tube was closed properly and shaken vigorously for 30s by the use of a vortex mixture for proper mixing. Again $4 \mathrm{~g}$ of anhydrous $\mathrm{MgSO}_{4}$ and $1 \mathrm{~g}$ of $\mathrm{NaCl}$ (Sigma-Aldrich, Analytical grade) were added and vigorous shaking was done for 1 minute to prevent the formation of magnesium sulfate aggregates. Then centrifuge tube containing sample with chemical mixture was kept at centrifuge machine (Sigma-3K30, Germany) and centrifuged at $5000 \mathrm{rpm}$ for 5 minutes. After centrifugation $3 \mathrm{~mL}$ of the supernatant (MeCN layer) was transferred into $15 \mathrm{~mL}$ micro centrifuge tube containing $120 \mathrm{mg}$ Primary Secondary Amone (PSA), $600 \mathrm{mg}$ anhydrous MgSO4 and $100 \mathrm{mg}$ of charcoal for cleaning up and thoroughly mixed by vortex for 30s. Then centrifuge tubes containing sample extract was placed in centrifuge machine and centrifuged at $4000 \mathrm{rpm}$ for 5 minutes. After centrifuge, a $1 \mathrm{~mL}$ supernatant was filtered through a $0.2 \mu \mathrm{m}$ PTFE filter using a syringe and taken in a clean vial for analysis in Gas Chromatography.

\subsection{Detection and quantification of pesticide residue in samples}

The concentrated extracts were analyzed by GC-2010 (Shimadzu) with Flame Thirmionized Detector (FTD) for detection of diazinon, quinalphos, fenitrothion, acephate, chlorpyriphos and dimethoate. The capillary column used was AT-1, length $30 \mathrm{~m}$, ID $0.25 \mathrm{~mm}$ and film thickness $0.25 \mu \mathrm{m}$. Helium was used as carrier and make up gas in FTD. The instrument parameters for GC-FTD were as follows: Injection port temperature was $260^{\circ} \mathrm{C}$, Column oven initial temperature was $160^{\circ} \mathrm{C}$ which went upto $240^{\circ} \mathrm{C}$ following $8 \mathrm{~min}$ incrimental time. Detector temperature was $280^{\circ} \mathrm{C}$, Stop time: $12 \mathrm{~min}$, Current: $0.5 \mathrm{pA}$, Makeup flow: $30 \mathrm{ml} / \mathrm{min}, \mathrm{H}_{2}$ Flow: $1.5 \mathrm{~mL} / \mathrm{min}$ and Air flow: $145 \mathrm{~mL} / \mathrm{min}$.

Before the injection of the sample extract, standard solutions of different concentrations of each pesticide were prepared and injected with selected instrument parameters. The samples were calibrated (retention time, peak area etc.) against three to four pointed calibration curve of standard solution of concerned pesticide. Each peak was characterized by its retention time. Sample results were expressed in $\mathrm{mg} / \mathrm{kg}$ automatically by the GC software which represented the concentration of the final volume injected. From this value, the actual amount of pesticide residue present in the sample was determined by using the following formula:

\section{Residue in sample $(\mathrm{mg} / \mathrm{kg})$}

Conc. obtained in injected volume $(\mathrm{mg} / \mathrm{kg}) \mathrm{X}$ Quantity of final volume $(\mathrm{L})$

Amount of sample taken $(\mathrm{kg})$

\section{Results}

The analytical results of both the vegetable samples for the detection of pesticide residue have been summarized in Tables 1 and 2. 
Table 1. Quantity of residue of pesticide estimated form hyacinth bean collected form nine different regions of Bangladesh.

\begin{tabular}{|l|l|l|l|l|l|}
\hline $\begin{array}{l}\text { SL } \\
\text { No. }\end{array}$ & Locations & $\begin{array}{l}\text { Samples } \\
\text { analyzed }\end{array}$ & $\begin{array}{l}\text { Contaminated } \\
\text { samples }\end{array}$ & $\begin{array}{l}\text { Detected residue } \\
(\mathbf{m g} / \mathbf{k g})\end{array}$ & $\begin{array}{l}\text { EU MRLs } \\
(\mathbf{m g} / \mathbf{k g})\end{array}$ \\
\hline 1 & Cox's bazar & 4 & - & ND & - \\
\hline 2 & Khagrachari & 4 & - & ND & - \\
\hline 3 & Barishal & 4 & - & ND & - \\
\hline 4 & Jamalpur & 4 & - & ND & - \\
\hline 5 & Dhaka & 4 & - & ND & - \\
\hline 6 & Cumilla & 4 & 1 & dimethoate: 0.192 & 0.01 \\
\hline 7 & Bogura & 4 & 2 & dimethoate: 0.961 & 0.01 \\
\cline { 3 - 6 } & & & & clorpyriphos: 0.082 & 0.05 \\
\hline 8 & Rangpur & 4 & 1 & dimethoate: 0.921 & 0.01 \\
\hline 9 & Rajshahi & 4 & 2 & dimethoate: $0.632,0.303$ & 0.01 \\
\hline
\end{tabular}

MRLs=Maximum residue limits; EU= European Union; $\mathrm{ND}=$ Not detected

Among 36 analyzed samples of hyacinth bean six samples (16.67\%) were contaminated with chlorpyriphos and dimethoate residues. The level of chlorpyriphos residue was $0.082 \mathrm{mg} / \mathrm{kg}$ and the level of dimethoate residues were $0.192 \mathrm{mg} / \mathrm{kg}, 0.961 \mathrm{mg} / \mathrm{kg}, 0.921 \mathrm{mg} / \mathrm{kg}, 0.632 \mathrm{mg} / \mathrm{kg}$ and $0.303 \mathrm{mg} / \mathrm{kg}$, respectively, all of them were above EU-MRLs. Dimethoate and clorpyriphos residue were found from four locations viz., Cumilla, Bogura, Rangpur and Rajshahi but the other five locations like Cox's bazar, Khagrachari, Barishal and Dhaka did not show any detectable residue.

Table 2. Quantity of residue of pesticide estimated form brinjal collected from nine different regions of Bangladesh.

\begin{tabular}{|l|l|l|l|l|l|}
\hline $\begin{array}{l}\text { SL. } \\
\text { No. }\end{array}$ & Locations & $\begin{array}{l}\text { Samples } \\
\text { analyzed }\end{array}$ & $\begin{array}{l}\text { Contaminated } \\
\text { samples }\end{array}$ & $\begin{array}{l}\text { Detected residue } \\
(\mathbf{m g} / \mathbf{k g})\end{array}$ & $\begin{array}{l}\text { EU MRLs } \\
(\mathbf{m g} / \mathbf{k g})\end{array}$ \\
\hline 1 & Cox's bazar & 4 & - & ND & - \\
\hline 2 & Khagrachari & 4 & - & ND & - \\
\hline 3 & Barishal & 4 & - & ND & - \\
\hline 4 & Jamalpur & 4 & - & ND & - \\
\hline 5 & Dhaka & 4 & - & ND & - \\
\hline 6 & Cumilla & 4 & - & ND & 0.01 \\
\hline 7 & Bogura & 4 & 1 & dimethoate: 0.032 & 0.01 \\
\hline 8 & Rangpur & 4 & 1 & quinalphos: 0.081 & 0.01 \\
\hline 9 & Rajshahi & 4 & 1 & dimethoate: 0.217 & 0.01 \\
\hline
\end{tabular}

MRLs=Maximum residue limits; $\mathrm{EU}=$ European Union; $\mathrm{ND}=$ Not detected

Out of 36 analyzed samples of eggplant, 3 samples $(8.33 \%)$ were contaminated with quinalphos $(0.081 \mathrm{mg} / \mathrm{kg})$ and dimethoate residues $(0.032 \mathrm{mg} / \mathrm{kg}$ and $0.217 \mathrm{mg} / \mathrm{kg})$ which were above UE-MRLs. Dimethoate residue was found in Bogura and Rajshahi region. Rangpur had quinalphos residue and the rest regions as Cox's bazar, Khagrachari, Barishal, Jamalpur, Cumilla and Dhaka did not found any detectable residue.

\section{Discussion}

A total of 36 analyzed samples of hyacinth bean collected from local market of nine different locations viz. Jessore, Cumilla, Norsingdi, Bogura, khagrachari, cox's bazaar, Mymensingh, Rangpur, Dinajpur, Ishurdi, Gazipur and Dhaka revealed that $16.67 \%$ samples were contaminated with dimethoate and chlorpyriphos residue. All of the detected levels of residue were above maximum residue limits provided by Europian Union (2016). Most of the contaminted samples had dimethoate residue. Chlorpyriphos residue was about to double $(0.082 \mathrm{mg} / \mathrm{kg})$ of the Eu-MRLs in Bogura region. But the detected dimthoate residues were 30- 92 times higher than EU-MRLs. In case of 36 analyzed samples of eggplant, 8.33\% samples were contaminated with quinalphos $(0.081 \mathrm{mg} / \mathrm{kg})$ and dimethoate residues $(0.032 \mathrm{mg} / \mathrm{kg}$ and $0.217 \mathrm{mg} / \mathrm{kg})$ which were also above EU-MRLs. Irrational and repeated use of pesticides in vegetables might cause the higher level of residues even at above MRL (Anon. 2001). Virgina and Bajet (1996) found residue of ogranophosphate insecticides (e.g. methomyl, triazophos, methyl parathion and diazinon) using rapid field kit from market basket samples of eggplant, tomato, 
cabbage and chinese peachy that exceeded MRL. El-Saeid and Selim (2013) found residues of organophosphorus, organochlorine, pyrethroid and carbamate from market vegetables (e.g. beans, eggplant, cauliflower, tomato, pepper, carrot, cucumber, squash, potato, onions and okra) that showed above the MRL in $15.89 \%$ of the total tested samples. Ahmed et al. (2013) found $38.67 \%$ brinjal samples were contaminated with six insecticides (viz., acephate, fenitrotion, qunalphos, cypermethrin, diazinon and malathion), of which $17.33 \%$ samples had residue above MRL irrespective of single or multiple residues. Ahmed et al. (2014) reported that $34.67 \%$ samples of hyacinth bean were contaminated with four insecticides (i.e. acephate, quinalphos, cypermethrin and fenitrothion), in which $12 \%$ of the samples contained residue above MRL. The results of the present study agreed with the works of the above authors. Detected residue of dimethoate, chlorpyriphos and quinalphos were found in the samples of four locations viz., Cumilla, Bogura, Rangpur and Rajshahi but the samples of other five locations like Cox's bazar, Khagrachari, Barishal, Jamalpur and Dhaka did not show any detectable residue which might safe for consumption.

\section{Conclusions}

Analyzed 72 samples of hyacinth bean and eggplant, $12.5 \%$ of the total samples were found contaminated with dimethoate, chlorpyriphos and quinalphos residues. Among the nine contaminated samples, $10 \%$ samples had dimethoate residue. Only one sample from Bogura contained chlorpyriphos residue in hyacinth bean and one sample from Rangpur had quinalphos residue in eggplant. But the major concern was, all of the detected residues had above EU-MRLs. The presence of pesticide residue exceeding MRLs in vegetables are detrimental to human consumption. So, regular monitoring programme on pesticide residue study in vegetables is needed for safe food production.

\section{Conflict of interest}

None to declare.

\section{References}

Ahmed MS, MA Sarder, MA Hoque, Ahmad M and KH Kabir, 2013. Determination of pyrethroid and organophosphorus insecticide residue in brinjal samples collected from some selected regions of Bangladesh. Bangladesh J. Entomol., 23: 39-51.

Ahmed MS, MA Sarder, MA Hoque, Ahmad M and KH Kabir, 2014. Quantification of commonly used insecticide residue in hyacinth bean collected from differtent regions of Bangladesh. Bangladesh J. Entomol., 24: 87-98.

Anonymous, 2001. Coordinated research on insecticide residue and resistance in major vegetables grown in Bangladesh. Report on Contact Research Project, BARC, BARI, Joydebpur, Gazipur, 102 p.

Antle JM and PL Pingali, 1994. Pesticides, Productivity, and Farmer Health: A Philippine Case Study. American Journal of Agril. Economics, 76: 418-430.

European commission, 2016. Europian union pesticides database.http://ec.europa.eu/food/plant/pesticides/eupesticides-database

EL-Saeid MH and MT Selim, 2013. Multiresidue analysis of 86 pesticides using Gas Chromatography Mass Spectrometry: II-nonleafy vegetables. Journal of Chemistry, 2013: 727149.

Hossain MI, G Shively and C Mahmood, 2000. Pesticide Expenditure in a Rice Vegetable Farming System: Evidence from Low-income Farms in Bangladesh, IPM-CRSP working paper 00-5.

Khatoon JA, MS Islam, NM Talukder and MA Hossain, 2004. Monitoring the residue level of three selected pesticides in Red Amaranth. J. Biol. Sci., 4: 474-479.

Trevisan MJ, GC Baptista, LRP Trevizan and G Papa, 2004. Residue of carbosulfan and its carbofuran metabolites and 3-hydroxy-carbofuran in oranges. Rev. Bras. Frutic. vol. 26 no. 2.

Virgina RO and CM Bajet, 1996. Pesticides in the Philippine environment. In: Proceedings. Anniversary and Annual Scientific Meeting, (Dizon, TD, Eusebio JE, Duenas JN, Palis FV and Mabbayad MO eds.). Pest Management Council of the Philippine, Davao City, pp. 61-77. 